\title{
Historical and recent change in extreme climate over East
} Asia

\author{
Guoyu Ren ${ }^{1,2}$ (D) Johnny C. L. Chan ${ }^{3} \cdot$ Hisayuki Kubota ${ }^{4} \cdot$ Zhongshi Zhang $^{1}$. \\ Jinbao $\mathrm{Li}^{5}$. Yongxiang Zhang ${ }^{2}$. Yingxian Zhang ${ }^{2}$. Yuda Yang ${ }^{6}$. Yuyu Ren ${ }^{2}$.

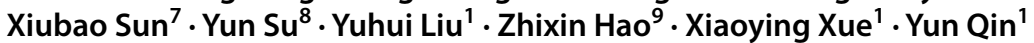

Received: 23 June 2021 / Accepted: 16 September 2021 / Published online: 22 October 2021

(c) The Author(s), under exclusive licence to Springer Nature B.V. 2021

\begin{abstract}
This is an extended editors' commentary on the topical collection "Historical and recent change in extreme climate over East Asia", which collects a total of 15 papers related to the change and variability of extreme climate events in East Asia over the last few hundreds years. The extreme climate events are broadly classified into three categories: temperature and extreme warmth/coldness, precipitation and floods/droughts and western North Pacific typhoons. This commentary briefly summarizes the main findings presented in each paper in this topical collection, and outlines the implications of these findings for monitoring, detecting and modeling of regional climate change and for studying climate change impacts and adaptability. It also assesses the uncertainties of these studies, as well as the remaining knowledge gaps that should be filled in the future. One solid conclusion we can draw from these studies is that there was a marked decadal to multi-decadal variability of extreme climate events in East Asia in recent history, and the extreme events as observed during the last decades of the instrumental era were still within the range of natural variability except for some of those related to temperature. More severe and enduring droughts occurred in the early 20 th century or the earlier periods of history, frequently leading to great famines in northern China. Uncertainties remain in reconstructing historical extreme climate events and analyzing the early instrumental records. Further research could focus on the improvement of methodology in proxy based reconstruction of multi-decadal variations of surface air temperature and precipitation/drought, the recovery, digitization, calibration and verification of the early instrumental records, and the mechanisms of the observed multi-decadal variability of extreme climate in the region.
\end{abstract}

Keywords Extreme climate $\cdot$ Change variability $\cdot$ East Asia $\cdot$ Temperature $\cdot$ Flood Drought · Typhoon · Global warming · Little Ice Age

This article is part of the topical collection on "Historical and recent change in extreme climate over East Asia," edited by Guoyu Ren, Danny Harvey, Johnny Chan, Hisayuki Kubota, Zhongshi Zhang and Jinbao Li

Guoyu Ren

guoyoo@cma.gov.cn

Extended author information available on the last page of the article 


\section{Introduction}

Change in the frequency of extreme climate events (ECEs) has received much attention in the last few decades. These ECEs have remarkably impacted the global and regional natural environment and human society, and their changes with time are also the key indicators in monitoring, detection, attribution, projection, and vulnerability assessment of climate change, at both regional and global scales (Smit et al. 2000; Giorgi et al. 2003; Alexander et al. 2009).

The East Asian region, which is characterized by high-density population, rapid economic growth, and frequent weather and climatic disasters associated with the unique monsoon climate, is highly vulnerable to change in ECEs on various time scales (Gong and Han 2004). Most observational studies showed detectable changes in ECEs over the last decades (Karl et al. 1996; Peterson et al. 2008; Alexander et al. 2009; Trewin and Vermont 2010; Zhang et al. 2019). Nonetheless, the studies for East Asia, like those for other regions, generally utilized short observational data usually beginning from the 1950s or 1960s due to the lack or unavailability of early instrumental data (e.g., Zhai et al. 2005; Ding and Ren 2008; Choi et al. 2009; Hulme et al. 2010; Ren et al. 2010, 2011; Lee et al. 2012) and high-resolution historical proxy data (Ding et al. 2007; Ge et al. 2016). The insufficiency of observations in the pre-1950s has hindered our understanding of the multi-decadal variability of ECEs in East Asia.

Efforts have been made to collect early instrumental data and high-resolution proxy records (Williamson, et al. 2018; Ge et al. 2016). Meanwhile, studies have investigated changes in ECEs in the historical era, including the last 150 years (Liang et al. 2009; Guo et al. 2011; Qian et al. 2015; Yu et al. 2020) and the Little Ice Age in East Asia (Shao et al. 2005; Zheng et al. 2006; Mikami 2008; Hao et al. 2010; Qin et al. 2020). The instrument-based analyses generally showed that, during the past 100-150 years, a significant trend appears in the time series of extreme temperature indices at a single station or in a local area, but no significant trend occurred in those of extreme precipitation, though they included remarkable decadal to multi-decadal variabilities (Liang et al. 2009; Guo et al. 2011; Yu et al. 2020). Studies of historical ECEs also revealed that several extremely severe droughts happened during the last 500 to 600 years in mainland China (Hao et al. 2010; Bai et al. 2019; Qin et al. 2020).

On 4-6 November, 2019, an Asian ACRE (The Atmospheric Circulation Reconstruction on Earth initiative; ACRE China, ACRE Japan, and ACRE Southeast Asia) Joint Workshop was held in Wuhan, China. Later, two additional workshops related to a national key R\&D project (supported by the Ministry of Sciences and Technology of China) were held in December 2019 in Beijing and Wuhan. The project that was initiated in May 2018 targeted the investigation of the facts and mechanisms of the ECE changes during the last 600 years over the East Asian monsoon region. These workshops turned out to be fruitful, and showcased a series of encouraging findings from past efforts.

This topical collection, entitled "Historical and recent change in extreme climate over East Asia," collects some of the novel research results presented at the above workshops. The 15 papers can be broadly classified into three categories: historical variations in the ECEs based on proxy reconstructions; the fact, mechanism, and impact of major historical ECEs in history; and the observed change and variability of ECEs in instrumental era. They can also be classified into three categories related to temperature, precipitation, and tropical cyclone. Figure 1 shows the distribution of the study areas or sites, the time periods or windows analyzed, and the types of data applied. These 


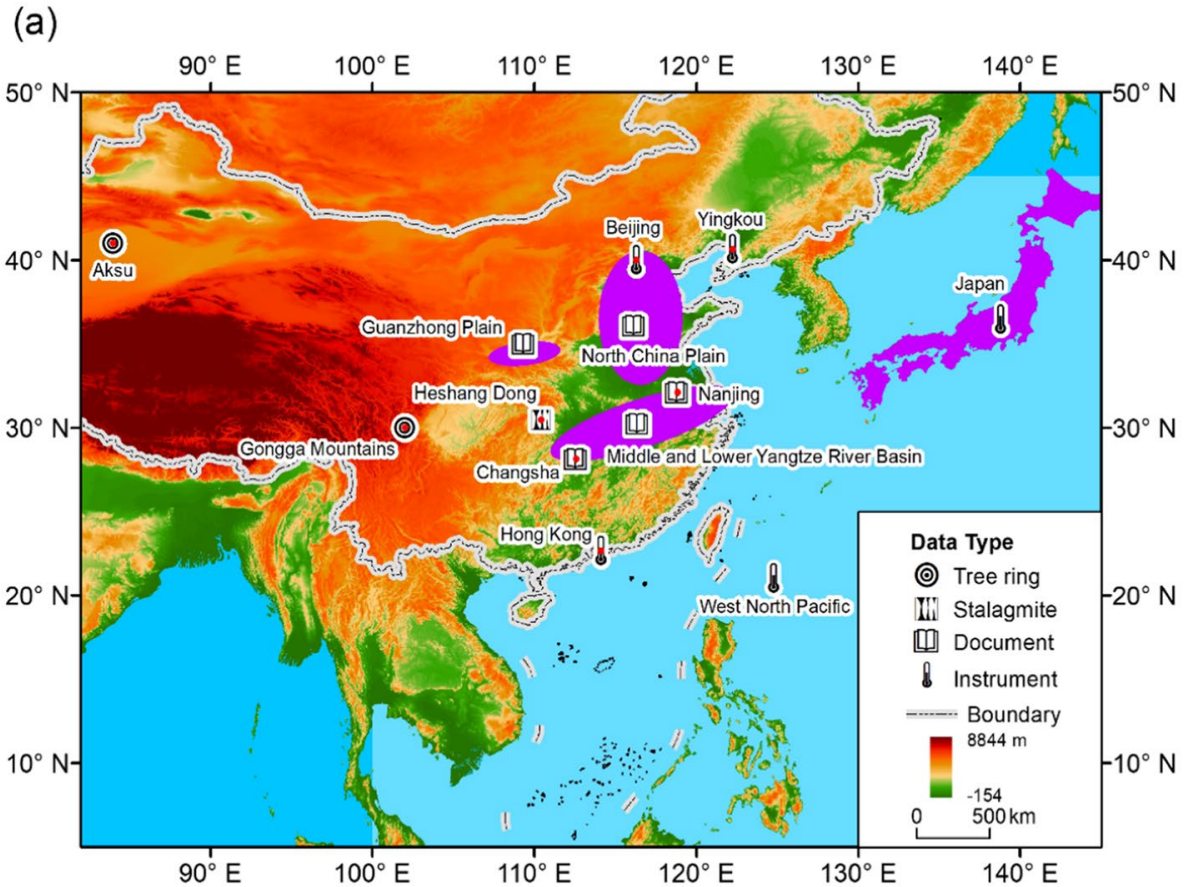

(b)

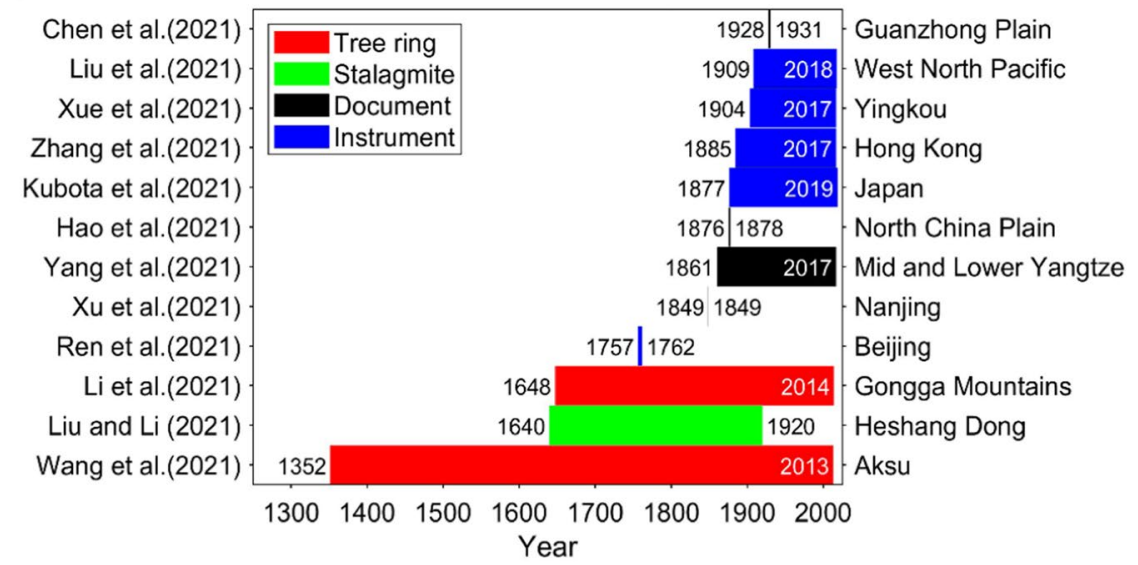

Fig. 1 Distribution of study areas and time periods of the studies in this topical collection over East Asia. a Study areas or sites. b Time period of each study. Numbers in $\mathbf{b}$ denote the start and end years of the data series. Also shown in $\mathbf{b}$ are the location and the type of these studies

studies will hopefully increase our understanding of historical and modern change in ECEs in this populous region. Specifically, the findings reported in these studies may help address the following questions:

1. What are the long-term changes and multi-decadal variabilities of ECEs during the past centuries? 
2. What is the natural variability of mean and extreme temperature during the pre-industrial revolution era, or how unusual was the last-half-century warming in comparison with historical temperature evolution?

3. What factors or mechanisms drove the observed changes, or abnormalities, of extreme climate during the historical era in East Asia?

4. What impacts did the historical mega-drought and severe floods exert on traditional agriculture and society, and how did the ancient society adapt to these major ECEs?

In this commentary, we firstly briefly summarize the main findings revealed in the 15 papers of the three categories mentioned above. We also discuss the implications of these findings for monitoring and detecting climate change, as well as the implication for understanding impacts and adaptability of climate change in East Asia. Furthermore, we point out the uncertainties of these studies, together with the knowledge gaps that should be filled in the future.

\section{Temperature and extreme cold/warms}

In this topical collection, four papers are related to the change or variability in mean and extreme temperature in East Asia on varied time scales. These studies were conducted based on tree-ring chronologies, historical documents, model outputs, and early instrumental records (Fig. 1), and they represent new inputs to the knowledge of regional historical and modern extreme temperature change.

\subsection{Reconstruction of historical minimum temperature series}

Based on a composite tree-ring chronology from the Gongga Mountains, southeastern Tibetan Plateau, Li et al. (2021) presented a reconstruction of winter (Dec-Mar) minimum temperature $\left(T_{\min }\right)$ during the past 367 years (1648-2014). The reconstruction showed three major cold periods (1670-1745, 1805-1853, and 1877-1949) and four major warm periods (1648-1669, 1746-1804, 1854-1876, and 1950-1998) during the past four centuries (Fig. 2a). The winter mean $T_{\min }$ variations reconstructed in the Gongga Mountains have a good consistency with those reported by other studies in the nearby areas. They further indicated that the $T_{\min }$ variations in the Gongga Mountains were strongly influenced by the shifts in phase of the Atlantic Multidecadal Oscillation (AMO), and the AMO might have been a key driving force affecting regional winter temperature over the past few centuries.

This study also showed a strong multi-decadal variability of winter $T_{\min }$ in the Gongga Mountains, with the switch of cold and warm phrases every 20 to 70 years (Fig. 2a). The influence of AMO on the winter $T_{\min }$ is not unexpected, because the study sites are well located within the mid- to upper tropospheric westerly belt during the wintertime, and the climate signal from northern Atlantic Ocean should be detectable in the tree-ring data. The variability of the reconstructed winter $T_{\min }$ series is consistent with other studies that reported a close linkage between the East Asian climate and the AMO on multi-decadal time scales (Li and Bates 2007; Li et al. 2009).

The last warm period (1950-1998) seems to be unprecedented in the last 367 years, with the winter $T_{\min }$ rising well above the background level of historical natural variability. This abnormal warming in the late twentieth century was also observed in the tree-ring studies in the Qilian Mountains, northeastern Tibetan Plateau (Liu et al. 2004) and central 
(a)

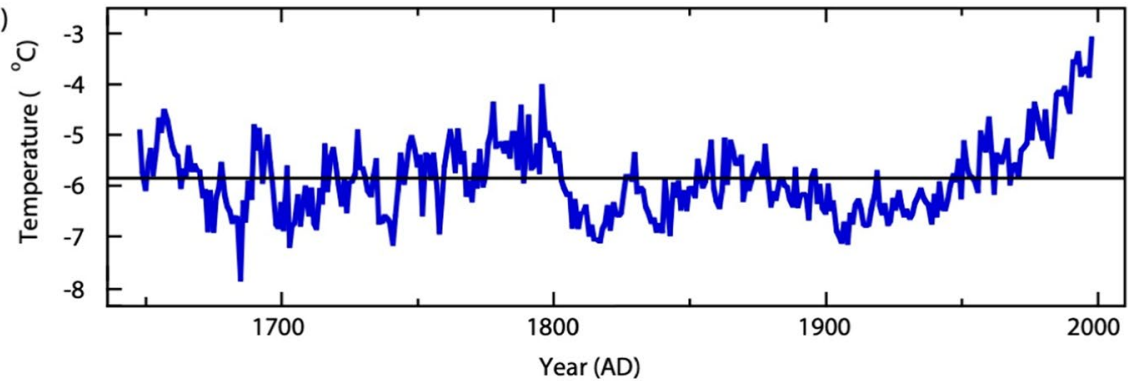

(b)

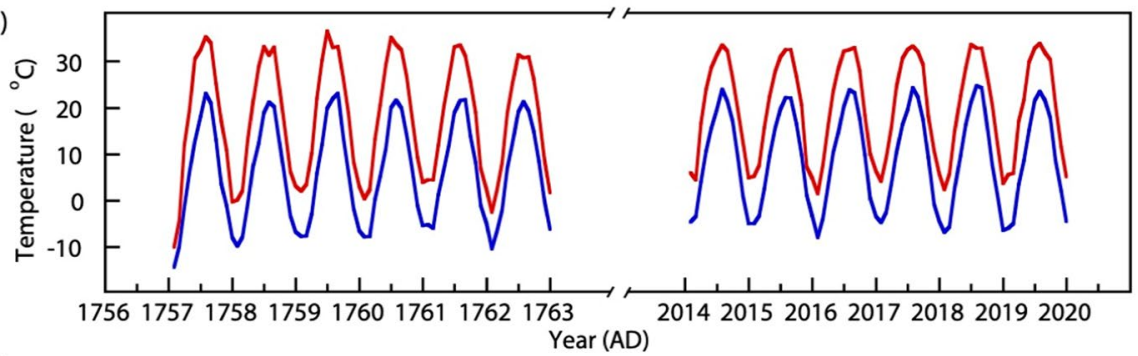

(c)

(d)

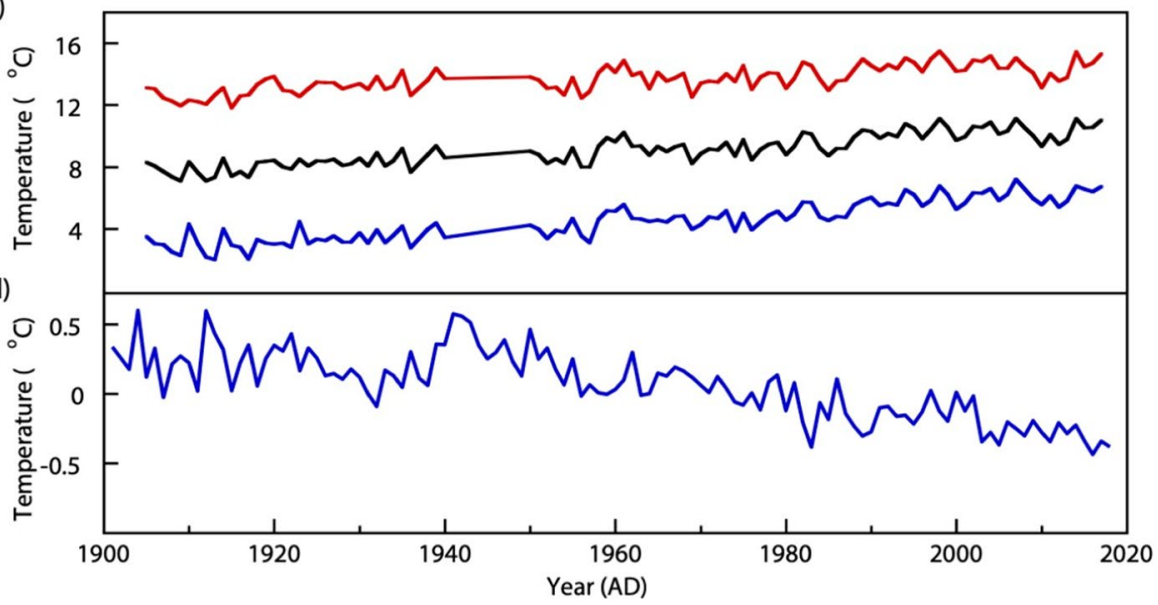

Fig. 2 Observed and reconstructed mean and extreme temperature in East Asia since 1400 AD. a Reconstructed winter (Dec-Mar) mean minimum temperature $\left(T_{\min }\right)$ during 1648-2014 at Gongga Mountains (Li et al. 2021). b Monthly mean maximum (red) and minimum (blue) temperatures of the early 6 years (17571762) and the recent 6 years (2014-2019) in central Beijing City (Ren et al. 2021). c Maximum (red), mean (black), and minimum (blue) temperatures at Yingkou during 1904-2017 (Xue et al. 2021). d Change in diurnal temperature range (DTR) anomalies in East Asia during 1901-2018 (Sun et al. 2021)

Himalayan Mountains (western Nepal) (Gaire et al. 2020). Assuming the robustness of the method used for removing the biological trend of tree growth, the reconstructed rapid warming might have been related to the combined effects of multi-decadal variability and anthropogenic global warming, as well as the fertilization effect of increased atmospheric $\mathrm{CO}_{2}$ concentration and the drying trend of the last decades in this area. It is also worth noting that the study area is located in the western rim of the Sichuan Basin, where annual mean and winter/spring mean surface air temperatures have experienced a weak cooling 
over the last half century (Ren et al. 2012; Wen et al. 2019) mainly due to the high emission of air pollutants and the calm wind in the lower troposphere to the leeward side of the Tibetan Plateau. However, the sampling sites may have well escaped from the influence of the aerosols due to the high altitudes (around $3800 \mathrm{~m}$ above sea level).

\subsection{Extreme temperature events of the pre-industrial era in Beijing}

Instrumental observation-based investigations of extreme temperature change generally utilized daily temperature data of the last few decades or a century. It would be interesting to know what happened to the instrument-recorded extreme temperature in the pre-industrial era (before the mid-eighteenth century). Ren et al. (2021) presented the first study of daily temperature of the mid-eighteenth century as compared to that in Beijing today. The observation was made by French Missionary Joseph Marie Amiot during 1757-1762 in the Old North Church located in central Beijing. This observation is probably the earliest and continuous daily instrumental temperature record that is longer than 1 year in East Asia. Based on an attempted homogenization of this early record with recent (2014-2019) records from four urban stations, it appears that the extreme minimum and maximum temperatures during the early 6 years were $-15.8^{\circ} \mathrm{C}$ (January 12,1762 ) and $43.1^{\circ} \mathrm{C}$ (June 5,1760$), 1.2^{\circ} \mathrm{C}$ and $1.9^{\circ} \mathrm{C}$ higher than during the $2014-2019$ period $\left(-17.0^{\circ} \mathrm{C}\right.$ and $\left.41.2^{\circ} \mathrm{C}\right)$. The two windows of time series are compared in Fig. 2 b. It is interesting to note that both the extreme minimum and maximum temperatures were higher in those early 6 years than in the recent 6 years of the four urban stations.

However, most other extreme temperature indices show a colder climate in the mideighteenth century than today. Within 1757-1762, the annual mean frost day and ice day counts were 126 days and 31 days respectively, while they were 110 days and 10 days during 2014-2019. The annual mean warm day and warm night counts were 63 days and 30 days respectively, compared to 65 days and 55 days at present; and the annual mean cool days and cold nights were 52 days and 48 days respectively, in comparison of $<40$ days and $<30$ days at present. Compared to those early 6 years, a large increase in warm nights ( 25 days) and a remarkable decrease in cold days ( $>12$ days) and cold nights ( $>18$ days) can be observed during the recent 6 years.

A similar warming trend in extreme temperature indices appeared in the last four to six decades. For example, the annual frost days and ice days decreased at rates of -3.48 days $/ 10$ years and -2.32 days/10 years respectively during 1961-2008 over China, equivalent to a decrease of 17 days and 11 days during the 48 years on average (Zhou and Ren 2011). The annual cold nights decreased significantly with a trend of -8.23 days/10 years; and annual warm nights increased significantly with a trend of 8.16 days/10 years over the whole of China, equivalent to a decrease of 40 days and an increase of 39 days, respectively (Zhou and Ren 2011). Therefore, the mean and extreme temperature in Beijing between 1757 and 1762 should be close to the early to mid-twentieth century, since those contrasts in the extreme temperature indices between the early and present 6 years were dominantly caused by the warming in the recent few decades. Nonetheless, this comparison is rough, without considering the influence of the specific location of modern observations, the urbanization effect, and the warming slowdown during the post-2000 period in China (Sun et al. 2017), which may result in an underestimation of the modern urban warming at the Old North Church and an overestimation of the warming trend in China on a whole during the last 60 years (1961-2020), although the effect would be relatively small (Ren and Zhou 2014). 


\subsection{The 100-year plus extreme temperature index series}

Continuous and longer than 100-year extreme temperature time series are important in understanding the causes and impacts of regional climate change, though they are lacking in most areas of East Asia due to the early economic and social systems and wars. Based on observations, Xue et al. (2021) analyzed the mean and extreme temperature changes from 1904 to 2017 at Yingkou station, Northeast China, and thus presented an important and continuous record longer than 100 years. Quality control and homogenization were conducted for the daily temperature data. They found significant warming trends in mean, maximum, and minimum temperatures (Fig. 2c). The minimum temperature increased (at the rate of $0.33^{\circ} \mathrm{C} / 10$ years) much more than the maximum temperature (at the rate of $0.07^{\circ} \mathrm{C} / 10$ years). Most extreme temperature indices show significant trends during these 114 years. The cold events witnessed a larger and more significant downward trend, when compared to warm events, which show a relatively weaker upward trend. This result agrees with the trend not only in China (Qian et al. 2007; Zhou and Ren 2011) but also in the global land area (Alexander et al. 2009; Zhang et al. 2019) during the past decades. They also found that the highest maximum temperature (1919) and the lowest minimum temperature (1920) record all occurred in the first half of the twentieth century, suggesting that the range of the extreme temperature variability is not getting larger under the background of global warming. At Yingkou station, the annual mean diurnal temperature range (DTR) showed the opposite trends in the first (positive) and second (negative) half of the twentieth century, which is consistent with a previous study of global land areas (Sun et al. 2018), as well as another paper of East Asia in this topic collection (Sun et al. 2021).

A stronger warming at the urban station, as compared to those in other regions, was noted. It is possible that urbanization around the observational sites has contributed to the larger trends, the asymmetric rise of maximum and minimum temperature, and the decrease of the DTR, during the entire period.

\subsection{Long-term change in diurnal temperature range (DTR)}

Long-term change in DTR is highly sensitive to external forcings. Sun et al. (2021) examined the long-term trend of DTR and its relationship with precipitation over East Asia from 1901 to 2018 . They show that the daily maximum $\left(T_{\max }\right)$ and minimum temperatures $\left(T_{\min }\right)$ had a significant asymmetric warming after the 1940s. The $T_{\min }$ increased much larger than $T_{\max }$, thus decreasing the DTR (Fig.2d). These results are consistent with the results in many previous studies (e.g., Zhai and Pan 2003; Qian et al. 2007; Ren et al. 2012). However, the upward trend from 1901 to the mid-1940s in the global land area (Sun et al. 2018) was not found over East Asia. They further show that annual total precipitation has a significant negative correlation with the annual mean DTR in the East Asian monsoon region, indicating that precipitation might have exerted a major influence on the DTR variability and trend. Urbanization also had a significant effect on the estimated decreasing trend of annual mean DTR since 1950 in China, in particular in North China (Ren and Zhou 2014). Preliminary analyses show that the contribution of urbanization was at least $21 \%$ to the negative DTR trend estimated in East Asia during 1950-2018, which is comparable to the earlier estimation for the period of 1961-2008 (Ren and Zhou 2014).

The linkage between the DTR and the precipitation revealed in this study agrees well with previous studies (Dai et al. 1999; Zhou et al. 2009; Liu et al. 2016). One of the 
underlying causes would be anthropogenic global warming, which resulted in the increase in atmospheric moisture, cloudiness, precipitation, and soil moisture, leading to the larger increase in $T_{\min }$ than that of $T_{\max }$, thus the decrease of DTR. In North China, however, urbanization can explain almost all the observed decrease of DTR over the last decades (Ren and Zhou 2014), which is closely associated with the enhanced urban heat island (UHI) intensity and the more concentrated aerosols in urban areas after the late 1970s.

\section{Extreme precipitation and floods/droughts}

In this topical collection, using proxy data of stalagmite, tree-ring, and historical documents, seven papers investigated extreme intense rainfall and floods, and unusually rainless years and severe droughts. One paper examines the synchronization of extreme tree-ring width values among various sites of East Asia by applying the method of complex network analysis. These studies mostly focus on the middle and lower reaches of the Yangtze River and the middle and lower reaches of the Yellow River, as well as the North China Plain (Fig. 1a). Three of the papers also consider the impacts of these extreme events on the social and economic system, together with the adaptation of society.

\subsection{Tree-ring-based reconstruction of drought in arid areas}

Droughts in temperate areas of East Asia have attracted much attention in climatological community, since they threaten rain-fed agriculture, water supply, and societal security. Based on a tree-ring width chronology of Schrenk spruce (Picea schrenkiana Fisch. et Mey.), Wang et al. (2021a, b) reconstructed the regional September-March Palmer Drought Severity Index (PDSI) in Aksu Area in the south slope of the Tianshan Mountains during the period of 1466-2013 AD. The mega-drought during the mid-sixteenth century (1540 s-1550 s) was especially pronounced, and a rapid wetting trend from the early 1980s to 2013 is also notable and consistent with instrumental observations (Fig. 3a). The authors identified 12 wet and 12 dry periods over the past 548 years, and the periodicity of 50 years and $2-3$ years. They suggested that the periodicity might have been related to the moisture variability of Central Asia, westerly circulation, and tropical ocean-atmosphere systems.

The rapid wetting trend since the 1980s in the tree-ring reconstruction has been affirmed by literatures (Shi et al. 2003; Ren et al. 2016) in the last two decades that investigated Northwest China including the central to eastern Tianshan Mountains. Although the comprehensive investigation by Wang et al. (2015) suggested an extremely unusual wetting trend in the late twentieth century (compared to the previous 250 years), it remains uncertain about whether the modern wetting trend as revealed in observations and reconstructions is unprecedented in the past centuries. This work (Wang et al., 2021a, b) further supports the claim that the current increase of precipitation (wetness) in this area is unusual from the historical perspectives, considering the uncertainty inherent in the climate reconstruction based on tree-ring and the 50-year periodicity of the PDSI series which may have been related to the impact of the AMO. If the conclusion could be further affirmed, the observed modern wetting trend in the Tianshan Mountains and probably in Northwest China could be more confidently attributed to global warming or local anthropogenic activities such as the expansion of irrigation and oasis areas on the piedmonts of the Tianshan Mountains. 


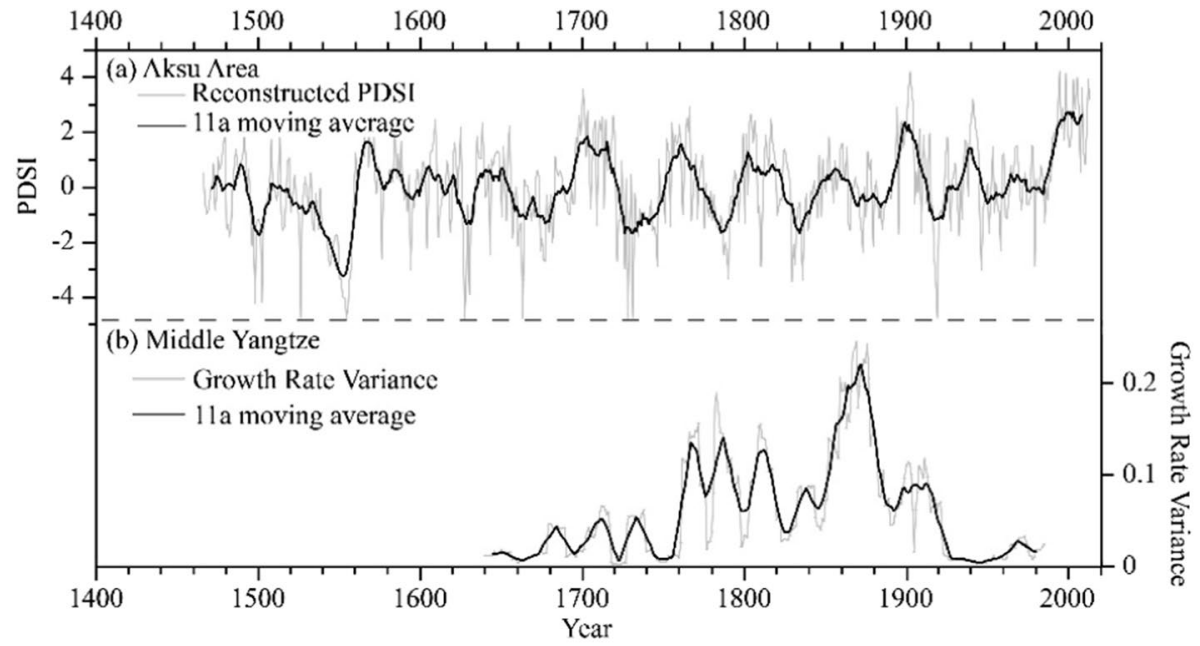

(c) Precipitation anomaly for 1876-1878

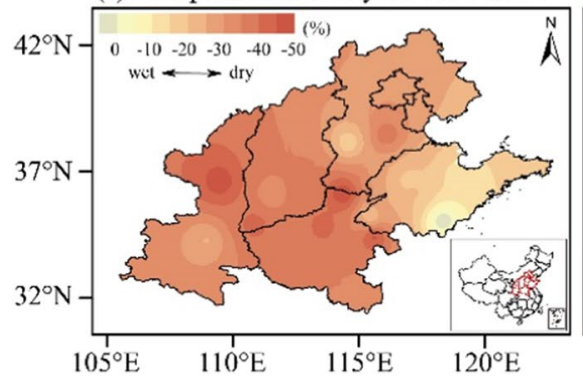

(d) Drought grade for 1483-1486 ^.D.

Fig. 3 Reconstructed mega-drought events since 1400 AD. a Tree-ring-based reconstruction of PDSI series in Aksu area, Tianshan Mountains (Wang et al., 2021a, b). b Growth rate variance of the stalagmite in the middle Yangtze River basin (with higher values indicating more precipitation and flood frequency) (Liu and Li 2021). c Spring-summer precipitation anomaly over 1876-1878 in North China (Hao et al. 2021). d Spatial distribution of average drought categories over 1483-1486 in northern China (Han and Yang 2021). The insets to the bottom right of $\mathbf{c}$ and $\mathbf{d}$ show the relative location of the areas in mainland China

\subsection{Stalagmite-based reconstruction of flooding frequency}

Liu and $\mathrm{Li}$ (2021) presented a stalagmite-based reconstruction of flooding frequency in the middle Yangtze catchment during the last centuries. Since there is a good correspondence between the 11-year running variance in stalagmite growth rate and the local flooding frequency recorded in historical documents, they used the variance in stalagmite growth rate as an indicator of local flooding frequency. The reconstruction shows that, in the middle Yangtze catchment, the flooding frequency became much higher during the late LIA, when compared to the early to mid LIA. Compared to the LIA, the flooding frequency reduced in the twentieth century (Fig. 3b). They attributed this higher flooding frequency to the regional cooler summer temperature during the LIA, and also suggested a possible linkage to El Niño/Southern Oscillation (ENSO).

Recently, Qin et al. (2020) established an updated chronology of Rock Fish emergence at White Crane Ridge (Baiheliang), which represents extremely low water levels that appeared in the Three-Gorge Area of the Yangtze River. The White Crane Ridge is located 
close to the stalagmite site investigated by Liu and Li (2021). The Rock Fish often submerged during 1501-1900. During the 50 years between 1601 and 1650, the Rock Fish never exposed. The lower frequency of emergence (compared to the pre-1501 and after1900 ) indicates fewer hydro-droughts, which is consistent with the relatively more frequent floods during the LIA reported in Liu and Li (2021). Qin et al. (2020) also suggested that the East Asian Summer Monsoon (EASM) was generally weak, which would lead to Meiyu rainfall becoming stagnant and lingering in the Yangtze and Huaihe River basins.

\subsection{Spatial pattern and causes of the 1876-1878 mega-drought}

A severe drought, called Ding-Wu Great Famine, occurred in North China in 1876-1878, causing wide range crop failure and millions of deaths. Based on historical documents, Hao et al. (2021) present a new investigation of the drought and the possible causes behind. They use the reconstructed high-resolution PDSI/precipitation data to examine the spatial patterns and the intensity of the drought. Furthermore, together with simulations, they diagnose the linkage between the severe drought and oceanic and atmospheric modes. The results indicate that the drought was most severe in the northern Henan province, southern Shanxi province, and northern Shaanxi province, with the spring-summer precipitation anomalies below $-30 \%$ (Fig. 3c). The authors attribute the 1876-1878 drought in North China to the strong El Niño under the background condition of positive PDO. The meridional disturbance of mid-latitude Rossby wave train accompanying the El Niño might have changed the position and strength of the troughs and ridges, blocking the moisture transport towards North China. The extremely abnormal climate that occurred concurrently in other regions during the 3 years, including the great famine in India and Southeast Asia, might have also been closely associated with the strong El Niño event.

\subsection{Impact and adaptation of the Guanzhong mega-drought}

An example of drought impact and adaptation is described by Chen et al. (2021). During 1927-1932, a mega-drought event occurred in the Guanzhong Plain and its neighboring areas, with the least precipitation in 1928-1929 (Liang et al. 2006; Zhang et al. 2011). By collecting and synthesizing records from newspapers, the authors were able to reconstruct the social impact of the extreme drought events in the Guanzhong Plain from 1927 to 1932, and to quantitatively describe the impact and response process. They find that the impact of the extreme drought had a cascade effect that did not involve a one-way and "step-by-step transfer" process, but a complex interaction of parallel effects. The negative impact was firstly felt after the season of summer and autumn harvest, and then was quickly passed onto the other sectors of economy and society due to the lack of resilience. The influence of any drought event was generally alleviated with the arrival of the harvest season, but in the case of successive years of droughts such as the Guanzhong mega-drought, the cumulative effect of the impact increased year by year and the resilience of social system rapidly decreased partly due to wars, which finally led to a complete failure of adaptation and a serious calamity. The famine caused deaths of more than a million in Shaanxi Province alone (Li 2006; Zeng et al. 2009).

The exact cause of the mega-drought needs to be investigated. It might have not been related to the ENSO events, as there was only a weaker ENSO event in 1925-1926. Moreover, it would be interesting to understand if the later deterioration of the economic and 
societal system during this mega-drought event could have any similarity with the Great Depression (1929-1933) in the central and western USA.

\subsection{The socio-economic consequences of a historical mega-drought}

The impact of drought goes far beyond crop failure and water shortage. It could also indirectly result in socio-economic transformation or even the collapse of dynasties in history. Han and Yang (2021) describe a possible route by which the lasting drought in the late fifteenth century might have caused the collapse of the Ming Dynasty. An extreme drought occurred in North China during 1483-1486, under the background of the overall drying period of the fifteenth century which accompanied the first cold phase (1450-1500) of the LIA. The most serious droughts with dryness index (drought grade) of 5th grade in 1484-1485 prevailed in most parts of the North China Plain and the Loess Plateau (Fig. 3d). The 4 years might have seen the most severe drought events in the past 1000 years, according to the authors. The lasting drought led to crop failure in large areas, deaths in huge numbers, and waves of migrants, as well as weakness in local and central financial reserve. The Ming Dynasty rulers were forced to reform the socio-economic system, which involved a transformation of the original military farm and Li Jia (an ancient Chinese system established to restrict population migrations) systems. The change relieved the pressure faced by the dynasty, but it also caused a wane of the state's control over society, which might have affected the socio-economic governance model of the Ming Dynasty and increased the vulnerability of the society to external disturbances, leading to the eventual collapse of the dynasty in the mid-seventeenth century when the Manchu troops and the new round of severe droughts simultaneously came about.

Here, Han and Yang (2021) present an example that shows the delayed societal system response to a historical severe drought. The severe drought could indirectly affect societal stability, when the government released an improper adaptation policy and lacked abilities in dealing with follow-up impacts of ECEs. This is a new understanding, since it is widely held that the Chongzhen mega-drought and the great famine of 1637-1643 were a direct or indirect factor in the collapse of the Ming Dynasty. It is also worth noting that both mega-droughts of 1484-1485 and 1637-1643 in North China occurred in the relatively cold stages of the LIA, and were caused probably by the weakened EASM due to the cooling of the Asian continent.

\subsection{The multi-decadal shifts of the Yangtze Meiyu belt}

The Meiyu (Baiu) rainfall is an important feature of the EASM, and its variability is a dominant factor for summer precipitation abnormality and floods in the Yangtze and Huaihe River basins, Korea, and southern Japan. Based on historical diaries and rain gauge measurements, Zheng et al. (2021) reconstructed the early summer intensive rainfalls at Changsha between 1861 and 2017. Changsha is located in the southern rim of the Meiyu rain belt. The reconstruction shows a clear inter-decadal to multi-decadal oscillation in the southern rim of the Meiyu rain belt. The oscillation can reach or even exceed one- to twodegree latitude. Between 1931 and 1999, a remarkable shift from the weak to the strong Meiyu rainfall happened at 1966-1967 (in the Meiyu rain belt between $28^{\circ} \mathrm{N}$ and $32.5^{\circ} \mathrm{N}$ ). The southern margin of the Meiyu rain belt $\left(26.5-28.5^{\circ} \mathrm{N}\right)$ also underwent a weak Meiyu rainfall in 1944-1990. The multi-decadal shifts of Meiyu rainfall seem to correlate with the EASM strength, and the AMO in a less extent. 


\subsection{Impact of traditional culture on adaptation to extreme floods}

Floods caused by rainstorms are another major hydro-climatic disaster in the southern parts of the East Asian monsoon region. The possibility of more intense precipitation under future anthropogenic warming and the approaches to effectively adapting to the extreme rainfall and floods have attracted much attention of both academic and governmental sectors. Xu et al. (2021) present a case where the countermeasures taken to cope with the severe flood in 1849 in Nanjing, China, were largely affected by traditional culture in addition to the societal and economic factors.

This rainstorm and flood event mainly occurred in the mid to lower reaches of the Yangtze River, causing severe losses in Jiangsu and Anhui provinces (Zhao et al. 2004). The scale of the disaster was worsened largely by the previous-year heavy rainfall and flood in the region. Xu et al. (2021) found that Feng Shui, also known as Chinese Geomancy, played an important role in the decision of whether or not to build a hydro project of drainage canal connecting the Xuanwu Lake with the Yangtze River before the flood. The proposed project was finally given up, because the local officials and elites of Nanjing city worried about the ruin of Feng Shui, bringing misfortune to local people. Without the project, the flood of 1849 inundated almost the whole Nanjing city, causing huge losses of residents' property. Learning from this lesson, however, the hydro project was eventually completed in 1931, showing that the relationship between traditional culture and the social adaptation to climate extreme has evolved over time.

\subsection{Synchronizations of climate events shown in tree-ring chronologies}

Although not specified through calibration and reconstruction, the tree-ring chronologies established for most areas of East Asia may mainly represent the variations of summer precipitation, thus regional drought or flood. Using the data of tree-ring width and the method of complex network, Wang et al. (2021a, b) analyzed the extreme values of tree-ring width and their synchronizations within different areas in East Asia during the past 600 years. The analysis shows stronger synchronizations in tree-ring width extremes of the Taiwan and Japan chronologies with those in inland areas of China mainland. They also show a remarkable shift in synchronization types within the south part and the inland sites during 1850-1950. For example, in-phase synchronizations of Taiwan with inland sites shifted to out-of-phase synchronizations after 1850. The out-of-phase synchronizations appeared within 5 sites during 1450-1650, but within 27 sites during the aft-1850 period. The shift suggests a potential reorganization in climate teleconnections, and probably a response of the East Asian climate system to global climate change.

\section{Western North Pacific typhoon}

Tropical cyclone (TC) or typhoon is a major extreme weather phenomenon in western North Pacific, causing serious damage to the East Asian countries each year. The western North Pacific is a region with the most frequent occurrences of TCs in the world. Although a large number of studies have examined the change of typhoons over the last decades, the changes of typhoons on centennial scale remain unclear. In this topical 
collection, three papers investigated the long-term change in TC (typhoon) frequency and tracks in western North Pacific and East Asia.

\subsection{Meridional oscillation of TC activity in the western North Pacific}

Typhoon maximum intensity in the western North Pacific in recent years has been found to have a northward shift based on observational data since the 1970s (Song and Klotzbach 2018). Using government observations and ship records, Liu et al. (2021) investigated whether such a shift also occurred in TC frequency and during the early twentieth century. They found a prominent meridional oscillation of the TC activity in the western North Pacific during the past 110 years. During 1943-1963 and 1997-2019, the TC numbers were higher near Japan, and lower over the South China Sea (SCS). However, an opposite pattern occurred during the periods of 1926-1942 and 1969-1988 (Fig. 4a, b). They attributed this meridional oscillation to the shifted TC genesis positions and their subsequent tracks associated with the decadal to multi-decadal variability of the large-scale atmospheric and oceanic circulation system.

This finding implies that the frequently reported decrease in the number of TCs in China mainland over the last decades, including the decreased precipitation induced by the TCs, cannot represent the change in the whole western North Pacific regions. It does not mean that other areas of the western North Pacific also underwent a downward trend of the TCs during the last decades, nor does it mean that the early period experienced a similar decrease in the TC frequency in China's mainland. The multi-decadal southnorth shift of the TC activity once again indicates the importance of broader spatial scale and longer temporal scale in the detection and attribution of the TC change in particular, and of mean and extreme climate change in general.

It is also worth noting that the finding points out the difficulty in detecting the anthropogenic signal in the regional TC data series, but it indeed helps understand the mechanism of decadal to multi-decadal variability of the TCs, and provides a clue to predict the possible trend of the TC frequency in the region in decades to come.

\subsection{Change in numbers of annual landfalling TCs in Japan}

There is a long observational record of TCs making landfall in Japan, and a potential to construct a landfalling TC time series of the past 100 years and more in the mid- to high latitude of the western North Pacific. Kubota et al. (2021) reported a long-term TC data series from 1877 to 2019 , which was obtained by combining the TC track data and the early observational data from weather stations and lighthouses. The lower number of annual landfalling TCs in Japan during the period from the 1970s to the 2000s as shown in this paper (Fig. 4c) is similar to that in China mainland (Ren et al. 2002; Ding and Ren 2008). Other periods, including the late nineteenth century, have a generally higher number of annual landfalling TCs in Japan. However, no significant trend in landfalling TCs is detectable for the entire period, although an increase in TC intensity and a significant northeastward shift of the TC landfalling locations could be found for the recent period of 1977-2019 (Fig. 4c), which is broadly consistent with the finding of Liu et al. (2021). 


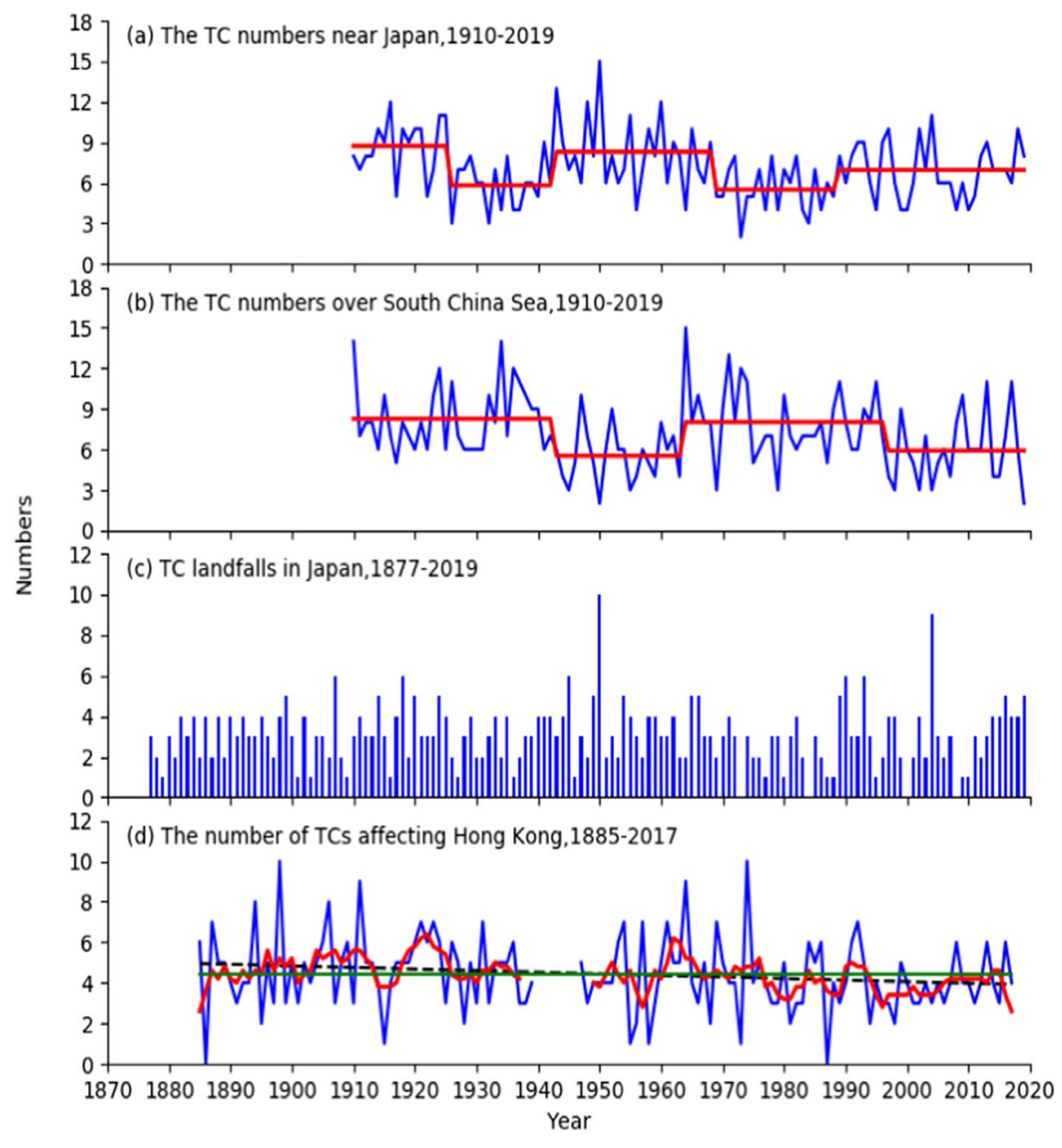

Fig. 4 Reconstructed typhoon (tropical cyclone (TC)) events since late-1880s over East Asia. a TC numbers near Japan from 1877 to 2019 (Liu et al. 2021). b TC numbers over the South China Sea from 1910 to 2019 (Liu et al. 2021). c TC landfalls in Japan from 1877 to 2019 (Kubota et al. 2021). d Number of TCs affecting Hong Kong from 1885 to 2017 (Zhang et al. 2021). Bold blue curves in a and b indicate the average TC numbers during different periods; Green line, blue curve, and red dashed line in d indicate the climatological mean, the 5a (5-year) running mean, and the liner trend, respectively

\subsection{Reconstruction of tropical cyclones affecting Hong Kong}

Pre-1950 TC observations are lacking in mainland China. The studies of TC change have focused mostly on the last five to six decades, and there is a lack of understanding for TC variation on a longer period in this region. Zhang et al. (2021) used the recently developed surface air pressure (SAP) data of the twentieth century, and a new methodology by defining the pressure-metric thresholds of observational sites affected by landfalling TCs at present, to reconstruct the landfalling TCs affecting Hong Kong over 1885-2017. The general distance of the detectable landfalling TCs and the SAP thresholds were determined 
by utilizing the correlation between the SAP indicators at Hong Kong station and those of each landfalling site for all 392 observed TCs during the period of 1951-2016. The reconstructed annual TC series show a visible long-term downward (but non-significant) trend from 1885 to 2017 , especially an obvious reduction after the early-1960s (Fig. 4d).

The significance of this work is mainly in the novel methodology for reconstructing TCs, which could be applicable in other areas, and would provide a homogeneous TC time series wherever the daily surface air pressure data are available. It also presents further evidence through the example of Hong Kong reconstruction that the TC frequency experienced no increases over the last 100 years or more, under the background of global warming since the late nineteenth century in the western North Pacific and China mainland.

To sum up, the TC frequency and intensity of the western North Pacific as a whole did not undergo a significant long-term trend during the last 100 years or more, in spite of the fact that the TCs decreased in frequency after the 1970s in the southern part of the region. The landfalling TCs in the coastal area of southern China also experienced a downward trend, but it is weak and non-significant statistically. The multi-decadal variability of TC frequency, including the decadal to multi-decadal shift of high-frequency TCs toward the north, may have been the main reason that the southern part of the western North Pacific saw a decrease in TC frequency and TC-induced precipitation.

Therefore, in the western North Pacific region, the possible response of the TC activity to global climate warming can still not be detected in the observations, despite the frequently reported simultaneous sea surface temperature increase in the western tropical Pacific and the SCS based on the historical SST observational data (e.g., Hartmann et al. 2013; Bao and Ren 2014).

\section{Concluding remarks}

The 15 papers included in the topical collection examine the change and variability of historical and modern ECEs in East Asia based on different sources of data. The results are broadly consistent with the previous studies and assessments. However, a number of findings will be conducive to a deeper understanding of regional climate and extreme climate change. The following conclusions can be drawn from the studies.

1. Large decadal to multi-decadal extreme temperature variabilities and huge inter-annual to decadal precipitation abnormalities occurred in East Asia in the last centuries, with some unexperienced in the last 100 years.

2. The extreme temperature change in the last century or decades seems unusual when compared to the historical reconstructions, but the recent extreme precipitation events are dwarfed by those that occurred in history.

3. Even if only focusing on the last century, changes in extreme temperature and precipitation frequency of the last decades are also different from those that happened in earlier decades.

4. The recent decline of the landfalling typhoon frequency in the southern part of East Asia is not a continuation of longer period downward trend, and it might have been a manifestation of the multi-decadal south-to-north shift of high-frequency TC belt.

5. The ocean-atmosphere-land interaction, including the East Asian monsoon abnormality, might be the dominant factor for the variability of the ECEs, but the extreme temperature change of the after-1900 period might have been a response to anthropogenic activity. 
6. The historical mega-droughts resulted in far more economic losses and deaths than any other ECEs, which might be because of the extremely low resilience of the ancient society to the extreme droughts.

Uncertainties still exist in the reconstruction of historical ECEs and the calibration of the early instrumental records. Further studies are needed to fill the knowledge gaps and reduce these uncertainties, by improving the proxy-based reconstruction methodology of multi-decadal temperature and precipitation (dryness index) variations, making an effort to recover, digitize, calibrate, and verify the early instrumental records, and exploring the mechanisms of the observed multi-decadal variability of extreme climate in the region.

Acknowledgements We appreciate the hard work by the editors of Climatic Change in the difficult circumstance of the COVID-19 pandemic. Our special thanks are due to L. D. Danny Harvey, Helen M. Poulos, Michael Oppenheimer, and Gary Yohe for their contributions to the topical collection. This work is supported by the National Key R\&D Program of China (2018YFA0605603; 2018YFA0605601; 2018YFA0605602).

\section{References}

Alexander LN, Tapper N, Zhang XB, Hayley J et al (2009) Climatic extremes: progress and future directions. Int J Climatl 29:317-319

Bai M, Zheng J, Hao Z, et al. (2019) Hydroclimate patterns over the Northern Hemisphere when megadroughts occurred in North China during the last millennium. Climatic Change 157. https://doi.org/10. 1007/s10584-019-02580-w

Bao B, Ren GY (2014) Climatological characteristics and long-term change of SST over the marginal seas of China. Cont Shelf Res 77(1):96-106

Chen XD, Su Y, Fang XQ (2021) Social impact of extreme drought events in Guanzhong area, Shaanxi Province during 1927-1932. Clim Change 164:27. https://doi.org/10.1007/s10584-021-02978-5

Choi G, Collins D, Ren GY, Trewin B et al (2009) Changes in means and extreme events of temperature and precipitation in the Asian-Pacific Network region, 1955-2007. Int J Climatol. https://doi.org/10.1002/ joc. 1979

Dai AG, Trenberth KE, Karl TR (1999) Effects of clouds, soil moisture, precipitation, and water vapor on diurnal temperature range. J Clim 12:2451-2473

Ding YH, Ren GY (eds) (2008) Introduction to climate change science of China. China Meteorological Press, Beijing, pp 63-100 (in Chinese)

Ding YH, Ren GY, Zhao ZC, Xu Y, Luo Y et al (2007) Detection, causes and projection of climate change over china: an overview of recent progress. Adv Atmos Sci 24(6):954-971

Gaire N, Fan Z, Shah SK, Thapa UK, Rokaya MB (2020) Tree-ring record of winter temperature from Humla, Karnali, in central Himalaya: a 229 years-long perspective for recent warming trend. Geogr Ann Ser B 102(13):1-20

Ge QS, Zheng JY, Hao ZX et al (2016) Recent advances on reconstruction of climate and extreme events in China for the past 2000 years. J Geogr Sci 26(007):827-854

Giorgi F, Bi X, Qian Y (2003) Indirect vs. direct effects of anthropogenic sulfate on the climate of East Asia as simulated with a regional coupled climate-chemistry/aerosol model. Climatic Change 58(3):345-376

Gong DY, Han H (2004) Extreme climate events in northern China over the last 50 years. Acta Geogr Sin 59(2):230-238 ((in Chinese))

Guo J, Ren GY, Ren Y (2011) Changes of mean and extreme temperatures in Tianjin in recent 100 years. Plateau Meteorology 30(5):1399-1405 ((in Chinese))

Han JF, Yang YD (2021) The socio-economic effects of extreme drought events in northern China on the Ming dynasty in the late 15th century. Clim Change 164:26. https://doi.org/10.1007/ s10584-021-02972-X

Hao ZX, Zheng JY, Ge QS (2010) Changes of extreme drought/flood events in eastern China over the past 2000 years. Climatic and Environmental Research 15(4):388-394 ((in Chinese)) 
Hao ZX, Bai MX, Xiong DY, Liu Y, Zheng JY (2021) Severe droughts of 1876-1878 in North China and possible causes. Climatic Change, 164. https://doi.org/10.21203/rs.3.rs-161952/v1

Hartmann DL, Klein Tank AMG, Rusticucci M et al (2013) Chapter 2 Observations: atmosphere and surface. The Physical Science Basis. Contribution of Working Group I to the Fifth Assessment Report of the Intergovernmental Panel on Climate Change [T. Stocker, D. Qin et al. eds.]. Cambridge University Press, Cambridge, United Kingdom and New York, NY, US

Hulme M, Zhao ZC, Jiang T (2010) Recent and future climate change in East Asia. Int J Clim, 14(6). https://doi.org/10.1002/joc.3370140604

Karl TR, Knight RW, Easterling DR et al (1996) Indices of climate change for the United States. Bull Am Meteorol Soc 77(2):279-292

Kubota H, Matsumoto J, Zaiki M et al (2021) Tropical cyclones since the mid-19th century over the western north Pacific. Clim Change 164:29. https://doi.org/10.1007/s10584-021-02984-7

Lee MH, Ho CH, Kim J et al (2012) Assessment of the changes in extreme vulnerability over East Asia due to global warming. Clim Change 113(2):301-321

Li YC (2006) Feng Yu-xiang's relief work of drought in Henan, Shaanxi and Gansu Provinces during Min Guo Period (1928-1930). Agricultural History of China 025(001):73-81

Li S, Bates GT (2007) Influence of the Atlantic Multidecadal Oscillation on the winter climate of east China. Advance in Atmospheric Sciences 24(1):126-135

Li SL, Wang YM, Gao YQ (2009) A review of the researches on the Atlantic Multidecadal Oscillation (AMO) and its climate Influence. Trans Atmos Sci 32(3):458-465

Li JX, Li JB, Li T, Au TF (2021) 351-year tree-ring reconstruction of the Gongga Mountains winter minimum temperature and its relationship with the Atlantic Multidecadal Oscillation. Clim Change 165:49. https://doi.org/10.1007/s10584-021-03075-3

Liang E, Liu X, Yuan Y (2006) The 1920s drought recorded by tree rings and historical documents in the semiarid and arid areas of northern China. Clim Change 79:403-432

Liang P, Chen BD, Chen BM (2009) Characterization of the precipitation changes in Shanghai during rainy seasons from 1873 to 2007. Resources Science 05:4-11

Liu KS, Chan JCL, Kubota H (2021) Meridional oscillation of tropical cyclone activity in the western North Pacific during the past 110 years. Clim Change 164:23. https://doi.org/10.1007/ s10584-021-02983-8

Liu L, Li Z, Yang X et al (2016) The long-term trend in the diurnal temperature range over Asia and its natural and anthropogenic causes. Journal of Geophysical Research: Atmospheres 121(7):3519-3533

Liu XH, Qin DH, Shao XM, Chen T, Ren JW (2004) Tree-ring based reconstruction of the past 1000year temperature change over the Qilian Mountains. Sciences in China (d) 34(1):89-95

Liu YH, Li ZL (2021) Stalagmite flooding frequency record since the middle Little Ice Age from Central China. Clim Change 164:28. https://doi.org/10.1007/s10584-021-02977-6

Mikami T (2008) Climatic variations in Japan reconstructed from historical documents. Weather 63(7):190-193

Peterson TC, Zhang XB, Brunet M, Vazquez-Aguirre JL (2008) Changes in North American extremes derived from daily weather data. J Gerontol Ser A Biol Med Sci 113:123-138

Qian C, Zhou W, Fong SK, Leong KC (2015) Two approaches for statistical prediction of non-Gaussian climate extremes: a case study of Macao hot extremes during 1912-2012. J Climate 28(2):623-636

Qian WH, Fu JL, Zhang WW, Lin X (2007) Changes in mean climate and extreme climate in China during the last 40 years. Adv Earth Sci 22(7):673-684 ((in Chinese))

Qin J, Shi AL, Ren GY, Chen ZH, Yang YD, Zou XK, Zhang PF (2020) Severe historical droughts carved on rock in the Yangtze. Bull Amer Mete Soc https://doi.org/10.1175/BAMS-D-19-0126.1

Ren FM, Gleason B, Easterling D (2002) Typhoon impacts on China's precipitation during 1957-1996. Advance in Atmospheric Sciences 19(5):943-952

Ren GY, Zhou YQ (2014) Urbanization effects on trends of extreme temperature indices of national stations over mainland China, 1961-2008. J Clim 27(6):2340-2360. https://doi.org/10.1175/ JCLI-D-13-00393.1

Ren GY, Ding YH, Zhao ZC, Zheng JY, Wu TW, Tang GL, Xu Y (2012) Recent progress in studies of climate change in China. Advance in Atmospheric Sciences 29(5):958-977

Ren GY, Chen Y, Zou XK, Zhou YQ, Ren YY, Jiang Y, Ren FM, Zhang Q, Wang XL, Zhang L (2011) Change in climatic extremes over mainland China based on an integrated extreme climate index. Climatic Research 50(1-2):113-124. https://doi.org/10.3354/cr01023

Ren GY, Feng GL, Yan ZW (2010) Progresses in observed studies of climatic extremes and changes in mainland China. Climatic and Environmental Research 15(4):337-353 ((in Chinese))

Ren GY, Yuan YJ, Liu YJ et al (2016) Changes in precipitation over Northwest China. Arid Zone Res 33(1):1-19 
Ren YY, Ren GY, Allan R, Zhang SQ et al (2021) Extreme temperature of the mid-18th century as compared to todays in Beijing. Clim Change 165:45. https://doi.org/10.1007/s10584-021-03063-7

Shao XM, Huang L, Liu HB et al (2005) Reconstruction of precipitation variation from tree rings in recent 1000 years in Delingha. Qinghai Science in China 48(7):939-949

Shi YF, Shen YP, Li DL et al (2003) Discussion on the present climate change from warm-dry to warmwet in Northwest China. Quaternary Sciences 23(2):152-164

Smit B, Burton I, Klein R, Wandel J (2000) An anatomy of adaptation to climate change and variability. Clim Change 45:223-251

Song J, Klotzbach PJ (2018) What has controlled the poleward migration of annual averaged location of tropical cyclone lifetime maximum intensity over the western North Pacific since 1961? Geophys Res Lett 45:1148-1156

Sun X, Ren G, Ren Y, Liu Y, Xue X (2017) A remarkable climate warming hiatus over Northeast China since 1998. Theoret Appl Climatol. https://doi.org/10.1007/s00704-017-2205-7

Sun XB, Ren G, You Q, Ren Y, Xu W, Xue X, Zhan Y, Zhang S, Zhang P (2018) Global diurnal temperature range (DTR) changes since 1901. Clim Dyn. https://doi.org/10.1007/s00382-018-4329-6

Sun XB, Wang CZ, Ren GY (2021) Changes of diurnal temperature range over East Asia from 1901 to 2018 and its relationship with precipitation. Clim Change 166:44. https://doi.org/10.1007/ s10584-021-03120-1

Trewin B, Vermont H (2010) Changes in the frequency of record temperatures in Australia, 1957-2009. Australian Meteorological and Oceanographic Journal 60:113-119

Wang T, Ren GY, Chen F, Yuan YJ, Wei WS (2015) An analysis of recent 300-year precipitation changes in the west-central Tianshan Mountains. Quaternary International 358: 48-57. doi: 10:1016/j. quaint.2014.10.051

Wang XJ, Xie FH, Zhang ZS et al. (2021) Complex network of synchronous climate events in East Asian tree-ring data. Climatic Change, 165, 54. https://doi.org/10.1007/s10584-021-03008-0

Wang HL, Zhang YX, Shao XM (2021b) A 548-year tree-ring-based drought reconstruction for the Aksu Area. West China Climatic Change 165:39. https://doi.org/10.1007/s10584-021-03021-3

Wen K, Ren G, Li J, Zhang A, Ren Y, Sun X, Zhou Y (2019) Recent surface air temperature change over mainland China based on an urbanization-bias adjusted dataset. J Clim 32:2691-2705

Williamson F, Allan R, Ren G, Lee T-C et al. (2018) Collating historic weather observations for the East Asian region: challenges, solutions and reanalyses. Adv Atmos Sci 35. https://doi.org/10.1007/ s00376-017-7259-z

Xu ZR, Yang YD, Sun T (2021) Feng Shui and imperial examinations: a case study on the 1849 severe flood in Nanjing and debates on flood discharge. Climatic Change 164:26. https://doi.org/10.1007/ s10584-021-03084-2

Xue XY, Ren GY, Sun XB, Zhang PF et al (2021) Changes in mean and extreme temperature at Yingkou station in China from 1904 to 2017. Clim Change 164:58. https://doi.org/10.1007/ s10584-021-02981-w

Yu XJ, Ren GY, Zhang PF, Hu JB, Liu N, Li JP and Zhang CC (2020) Extreme temperature change of the last 110 years in Changchun, Northeast China. Adv Atmos Sci 37 (4). https://doi.org/10.1007/ s00376-020-9165-z

Zeng Z, Fang X, Ye Y, Zhang X (2009) Disaster losses and causes of three extreme droughts in China over the past 300 years. Journal of Catastrophology 24(2):116-122

Zhai PM, Pan XH (2003) Trends in temperature extremes during 1951-1999 in China. Geophys Res Lett 30. https://doi.org/10.1029/2003G1018004

Zhai PM, Zhang XB, Wan H, Pan XH (2005) Trends in total precipitation and frequency of daily precipitation extremes over China. J Clim 18:1096-1108

Zhang DE, Demaree G (2004) Extreme warm in the North China summer of 1743: a study of hot historical summer events in a relatively warm climate. Chin Sci Bull 49:2204-2210

Zhang PF, Ren GY, Xu Y, Qin Y, Sun XB, Wang XL (2019) Observed change in extreme temperature over the global land based on the newly developed CMA daily dataset. J Clim 32:8489-8509. https://doi.org/10.1175/JCLI-D-18-0733.1

Zhang Y, Shao XM, Yin ZY, Liang EY et al (2011) Characteristics of extreme droughts inferred from tree-ring data in the Qilian Mountains during the period 1700-2005. Climate Res 50(1-2):141-159

Zhang YX, Ren YY, Ren GY, Zhang YQ et al (2021) Surface-air-pressure based reconstruction of tropical cyclones affecting Hong Kong since the late 19th century. Clim Change 164:57. https://doi.org/ 10.1007/s10584-021-03028-w

Zhao HX, Zheng JY, Ge QS (2004) Reconstruction and analysis of major floods events in Jiangsu and Anhui provinces in 1755 and 1849. Meteorological Science 24(4):460-467 
Zheng JY, Wang WC, Ge QS, Man ZM, Zhang PY (2006) Precipitation variability and extreme events in eastern China during the past 1500 years. Terrestrial Atmospheric and Oceanic Sciences 17:579-592 ((in Chinese))

Zheng WW, Yang YD, Man ZM (2021) The multiply characteristics on the movement of the Meiyu rainbelt in East Asia: reconstructing the historical data on southern margin of the Meiyu between 1861 and 2017. Climatic Change, 165(1). https://doi.org/10.1007/s10584-021-03007-1

Zhou LM, Dai AG, Dai YJ et al (2009) Spatial dependence of diurnal temperature range trends on precipitation from 1950 to 2004. Clim Dyn 32(2/3):429-440

Zhou YQ, Ren GY (2011) Change in extreme temperature events frequency over mainland China during 1961-2008. Climate Res 50(1-2):125-139. https://doi.org/10.3354/cr01053

Publisher's note Springer Nature remains neutral with regard to jurisdictional claims in published maps and institutional affiliations.

\section{Authors and Affiliations}

\section{Guoyu Ren ${ }^{1,2}$ (D) Johnny C. L. Chan ${ }^{3} \cdot$ Hisayuki Kubota ${ }^{4} \cdot$ Zhongshi Zhang $^{1}$. Jinbao $\mathrm{Li}^{5}$. Yongxiang Zhang ${ }^{2}$. Yingxian Zhang ${ }^{2}$. Yuda Yang ${ }^{6} \cdot$ Yuyu Ren ${ }^{2}$. Xiubao Sun ${ }^{7}$ Y Yun Su ${ }^{8}$. Yuhui Liu ${ }^{1}$ Zhixin $\mathrm{Hao}^{9} \cdot \mathrm{Xiaoying} \mathrm{Xue}^{1} \cdot$ Yun Qin $^{1}$}

1 Department of Atmospheric Science, School of Environmental Studies, China University of Geosciences (CUG), Wuhan, China

2 Laboratory for Climate Studies, National Climate Center, China Meteorological Administration (CMA), Beijing, China

3 City University of Hong Kong (CityU), Hong Kong, China

4 Hokkaido University, Sapporo, Japan

5 Hong Kong University (HKU), Hong Kong, China

6 Fudan University, Shanghai, China

7 Institute of South China Sea, Chinese Academy of Sciences (CAS), Guangzhou, China

8 Beijing Normal University (BNU), Beijing, China

9 Institute of Geographic Sciences and Natural Resources Research, Chinese Academy of Sciences (CAS), Beijing, China 